\title{
Gastric Xanthoma: To Remove or not to Remove?
}

\author{
Tarek Nammour ${ }^{1}$, Rayan Rammal ${ }^{2}$ and Jana G Hashash ${ }^{1 *}$
}

${ }^{1}$ Division of Gastroenterology, American University of Beirut, Lebanon

${ }^{2}$ Department of Pathology, American University of Beirut, Lebanon

\section{Keywords}

Gastric xanthoma, Gastric xanthelasma, Gastric polyp, Endoscopy

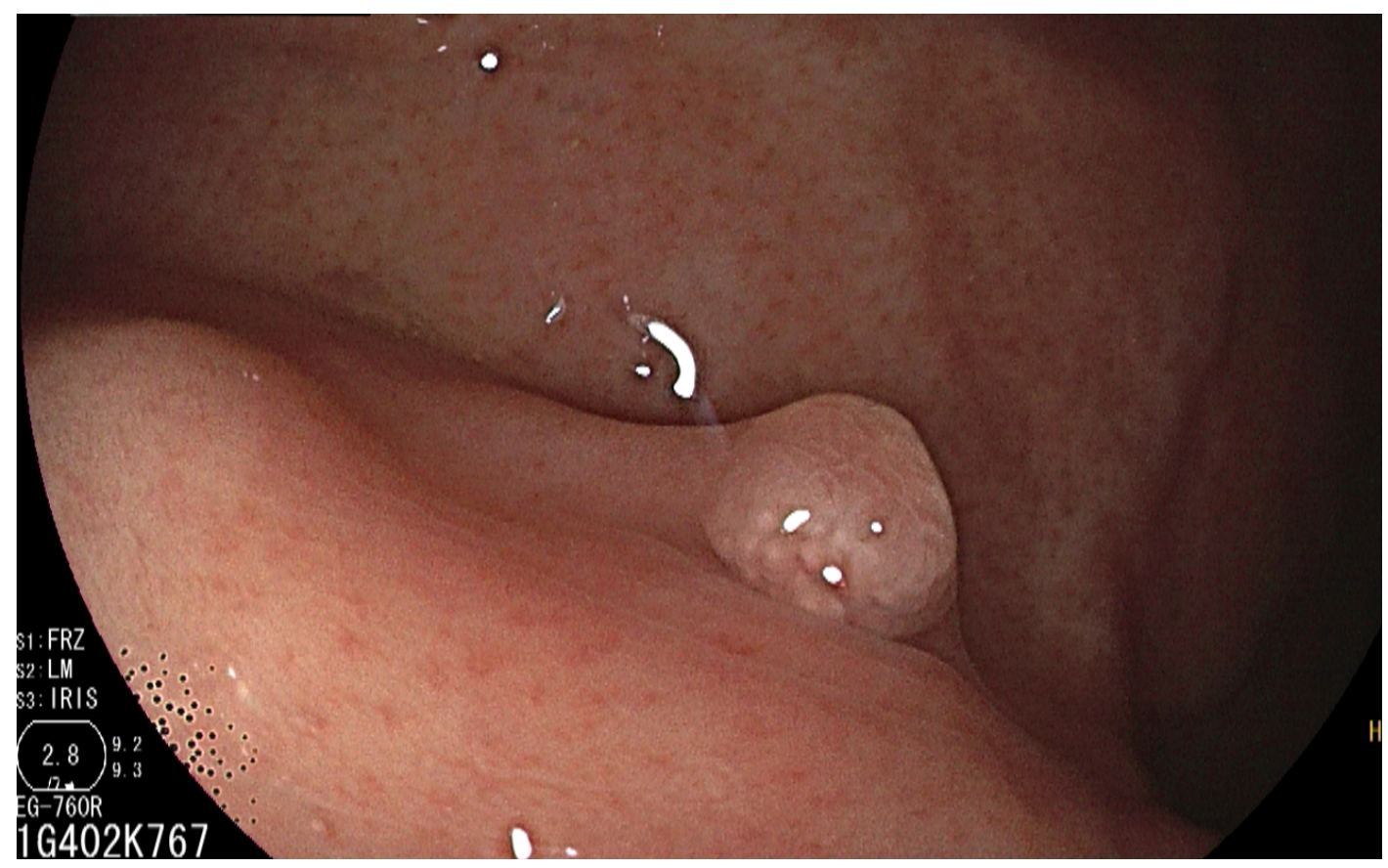

Figure 1: Endoscopic image of the gastric polyp.

A 36-year-old healthy male presented for evaluation of chronic diarrhea and post-prandial epigastric abdominal pain. He denied any other gastrointestinal symptoms. Physical examination was unremarkable. Upper endoscopy showed a single $5 \mathrm{~mm}$ sessile polyp in the gastric fundus (Figure 1) and was otherwise unremarkable. The gastric polyp was completely removed and pathology showed foamy macrophages in the lamina propria and mild chronic inflammation (Figure 2). Gastric xanthomas (GX) are rare incidentally encountered non-neoplastic lesions. Incidence rates range from $0.2-0.8 \%$ [1] with the stomach being the most common site, specifically the gastric antrum. GX are typically small $(<5 \mathrm{~mm})$, well-demarcated, yellow-white plaques/nodules that may arise as single or multiple lesions [2]. Histologically, GX are composed of lipid-contain- ing foamy histiocytes in the lamina propria of the gastric wall [3]. Abnormalities in lipid metabolism or gastric mucosal inflammation have been postulated as possible causes for the development of GX. Several studies reported a rela-

*Corresponding author: Jana G Hashash, MD, MSc, Assistant Professor of Medicine, Division of Gastroenterology, American University of Beirut, Lebanon, Tel: +961-1-374374, Fax: +961$1-365612$

\section{Accepted: March 29, 2020}

Published online: March 31, 2020

Citation: Nammour T, Rammal R, Hashash JG (2020) Gastric Xanthoma: To Remove or not to Remove?. J Gastrointest Hepat Surg 3(1):30-31 


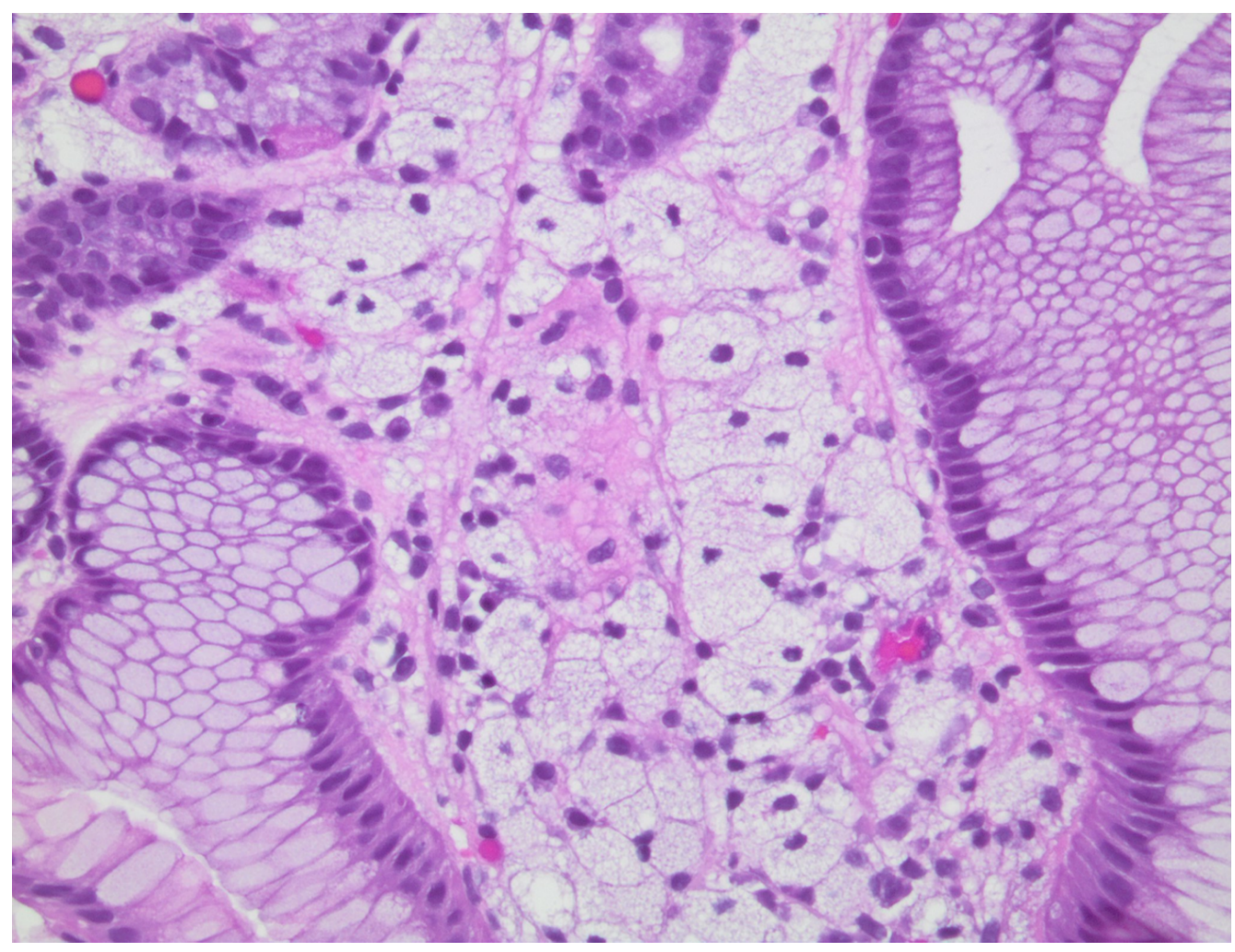

Figure 2: Gastric biopsy showing a large aggregate of foamy macrophages (Hematoxylin and Eosin stain).

tionship between GX formation and various gastric insults such as Helicobacter pylori infection, atrophic gastritis, and gastric cancer [2]. To date, there are no recommendations for treatment of GX. With the absence of long-term follow-up studies on these benign, asymptomatic, incidental lesions, it remains unclear whether GX should be excised completely or followed up routinely.

\section{Conflicts of Interest}

No conflicts of interest exist.

\section{Sources of Funding}

None.

\section{Author's Contributions}

T Nammour: Acquisition of data, Analysis and interpretation of data, Drafting of the manuscript.

\section{R Rammal: Acquisition of data.}

JG Hashash: Study concept and design, Acquisition of data, Analysis and interpretation of data, Drafting of the manuscript, and critical review of the manuscript.

\section{References}

1. Alzahrani M, Alqunaitir A, Alsohaibani M, et al. (2018) Gastric xanthelasma associated with hyperplastic polyp and mucosal erosions: Report of an unusual case and literature review. Oxf Med Case Reports.

2. Kitamura S, Muguruma N, Okamoto K, et al. (2017) Clinicopathological assessment of gastric xanthoma as potential predictive marker of gastric cancer. Digestion 96: 199-206.

3. Shibukawa N, Ouchi S, Wakamatsu S, et al. (2019) Gastric xanthoma is a predictive marker for early gastric cancer detected after helicobacter pylori eradication. Intern Med 58: 779-784.

DOI: $10.36959 / 879 / 377$ 